\title{
Effect of add-on therapy of tiotropium in COPD treated with theophylline
}

\author{
Tomotaka Kawayama' \\ Tomoaki Hoshino' \\ Masao Ichiki $^{2}$ \\ Toru Tsuda ${ }^{3}$ \\ Masaharu Kinoshita ${ }^{4}$ \\ Shohei Takata ${ }^{5}$ \\ Takeharu Koga' \\ Tomoaki Iwanaga' \\ Hisamichi Aizawa' \\ Kurume COPD Study \\ Group* \\ 'Department of Medicine, Kurume \\ University School of Medicine, \\ Kurume, Japan; ${ }^{2}$ Division of \\ Respiratory Medicine, National \\ Hospital Organization Kyushu Medical \\ Center, Fukuoka, Japan; ${ }^{3}$ Tsuda \\ Hospital, Kitakyushu, Japan; ${ }^{4}$ Nagata \\ Hospital, Yanagawa, Japan; ${ }^{5} \mathrm{National}$ \\ Hospital Organization Fukuoka- \\ Higashi Medical Center, Fukuoka, \\ Japan
}

\begin{abstract}
Background: Although combination therapy with bronchodilators is recommended for chronic obstructive pulmonary disease (COPD), there is insufficient evidence for the efficacy of some combinations of long-acting bronchodilators.
\end{abstract}

Objective: We investigated the effects of a combination therapy with tiotropium and theophylline in COPD patients.

Methods: In a 12-week, open-labeled, parallel-group randomized study, pulmonary functions and dyspnea scores were compared between the combination and theophylline alone therapy at baseline, and 4 and 8 weeks after randomization in COPD.

Results: Sixty-one COPD patients completed the trial (31 combination therapy, 30 theophylline alone; mean age 70 years; 58 males; mean dyspnea score 2.0 and forced expiratory volume in one second $\left(\mathrm{FEV}_{1}\right) 1.5 \mathrm{~L}\left[62.5 \%\right.$ predicted]). $\mathrm{FEV}_{1}$ in the combination group, but not in the theophylline alone, was significantly increased at $4(1.56 \pm 0.13 \mathrm{~L}, \mathrm{p}<0.001)$ and 8 weeks $(1.60 \pm 0.13 \mathrm{~L}, \mathrm{p}<0.001)$ from the baseline $(1.40 \pm 0.12 \mathrm{~L})$. In the combination group, but not the theophylline alone group, the dyspnea score was significantly improved after 4 ( $p<0.01)$ and 8 weeks $(p<0.05)$ compared with baseline. In 17 patients who did not receive theophylline at screening, treatment with 4 or 8 weeks of theophylline alone did not improve dyspnea score or $\mathrm{FEV}_{1}$.

Conclusion: Addition of tiotropium therapy to theophylline treatment can improve dyspnea and pulmonary function in COPD. Although this study did not assess whether there was any benefit of adding theophylline to patients treated with tiotropium, tiotropium can be a useful addition in COPD already treated with theophylline.

Keywords: chronic obstructive pulmonary disease, long acting anticholinergics agent, tiotropium, slow release theophylline, combination therapy

\section{Introduction}

Chronic obstructive pulmonary disease (COPD) is characterized by progressive airway obstruction, chronic respiratory symptoms, and impaired health status, and it is a leading cause of morbidity and morality worldwide (Gold 2006). COPD is treatable, and pharmacological treatment is effective in controlling symptoms and health status. In particular, the use of bronchodilators plays a central role in the pharmacological treatment of symptomatic COPD patients. Bronchodilators improve airway obstruction, symptom control, health status, and health-related quality of life (QOL), and they reduce the frequency of exacerbations (Donohue 2005; Gold 2006).

Tiotropium bromide is a long-acting anticholinergic that provides sustained bronchodilation through prolonged $\mathrm{M}_{3}$ muscarinic receptor blockade (Disse et al 1999). Previous studies have shown that inhaled tiotropium improves pulmonary function, dyspnea, and QOL in COPD to a significantly greater extent than placebo or the short-acting anticholinergic ipratropium (Casaburi et al 2002; Vincken et al 2002). Tiotropium also reduces COPD exacerbations and may reduce related utilization of
Correspondence: Hisamichi Aizawa Department of Medicine, Kurume University School of Medicine, 67 Asahimachi, Kurume 830-00I I, Japan

Tel +8I 942317560

Fax +81 942317703

Email aizawa@med.kurume-u.ac.jp 
health-care facilities in patients with moderate to severe COPD (Niewoehner et al 2005; Dusser et al 2006). Furthermore, one recent study based on a retrospective 1-year analysis has raised the possibility that tiotropium is associated with a reduced rate of loss of forced expiratory volume in 1 second $\left(\mathrm{FEV}_{1}\right)$ (Anzueto et al 2005).

Oral slow-released theophylline is used widely as a bronchodilator worldwide (Turner-Warwick 1957; Jackson et al 1964; Mitenko and Ogilvie 1973). Previous studies have reported that long-term theophylline use for COPD results in improvement of pulmonary functions, including vital capacity (VC), $\mathrm{FEV}_{1}$, minute ventilation, and gas exchange (Murciano et al 1989). Theophylline also has a beneficial effect on exercise endurance in COPD (Guyatt et al 1987). Recent studies have shown that theophylline reduces the numbers of neutrophils and concentrations of interleukin-8 in the airways of COPD patients (Culpitt et al 2002). Low-dose theophylline can also prevent oxidative stress, and it restores corticosteroid responsiveness (Ito et al 2002). These results suggest that theophylline has anti-inflammatory effects in COPD, as it does in asthma (Sullivan et al 1994).

The GOLD (Global Initiative for Chronic Obstructive Lung Disease) guidelines recommend combination therapy with different potential bronchodilators for the pharmacological treatment of COPD (Gold 2006). Theophylline has an additional effect in the clinical improvement of COPD when it is used in combination with a long-acting $\beta_{2}$-agonist (LABA) (Zuwallack et al 2001). However, few investigations have reported the efficacy of combination therapy with inhalation of the long-acting anticholinergic tiotropium and oral administration of slow-release theophylline in COPD patients. In Japan, theophylline is prescribed for most COPD patients (Ichinose et al 2006). Our purpose was to investigate the efficacy and safety of add-on treatment with tiotropium in COPD patients treated with theophylline.

\section{Material and methods}

The study was performed at Kurume University Hospital and at each medical institute of the Kurume COPD Study Group. The protocol was designed in accordance with good clinical practice and the latest revisions to the Declaration of Helsinki, and was approved by the institutional ethics committees of Kurume University and each medical institute.

\section{Subjects}

COPD patients $\geq 40$ years old and with a cigarette smoking history of $\geq 10$ pack-years and respiratory symptoms related to COPD were enrolled in the study. All patients were diagnosed on the basis of clinical history, physical examination, chest X-ray, chest computed tomography, and pulmonary function tests, in accordance with the clinical criteria for the diagnosis and severity of COPD by the GOLD guidelines (Gold 2006). Patients with a history of asthma, atopy, absolute peripheral eosinophil count $>600 \mathrm{~mm}^{3}$, and/or reversibility of $\mathrm{FEV}_{1}$ by $>200 \mathrm{~mL}$ and $>12 \%$ after inhalation of $200 \mu \mathrm{g}$ salbutamol were carefully excluded. Patients who had a history of renal failure, moderate to severe prostatic hypertrophy or bladder-neck obstruction, narrow-angle glaucoma, heart failure, arrhythmia, bronchiectasis, pneumoconiosis, old mycobacterial infections, interstitial pneumonia, mental disorders, lung surgery, or any malignancies were also excluded. Five patients (16.6\%) in the theophylline alone group and two patients $(6.5 \%)$ in the combination group were being treated with inhaled corticosteroids at the screening visit. There was no significant difference of number between the two groups $(p=0.2554)$. Written informed consent was obtained from all patients.

\section{Study design}

The study was performed over a 12-week period. We used an open-labeled, parallel-group, randomized design to compare the efficacy and safety of the addition of $18 \mu \mathrm{g}$ inhaled tiotropium once daily to theophylline in stable COPD patients. The primary end-point for this study was the change in $\mathrm{FEV}_{1}$ from baseline to the end of 8 weeks after treatment, and the secondary end-points were the British MRC (Medical Research Council) dyspnea scale and forced vital capacity (FVC).

At the first visit, each patient underwent recording of medical, occupational, and smoking history; physical examination; chest radiography, including high-resolution computed tomography; electrocardiogram; blood testing; and spirometry as screening tests to ensure that they met the inclusion criteria. The spirometry was performed before and after inhalation of a bronchodilator at the first visit. Dyspnea was scored using the British MRC dyspnea scale (Moor-Jankowski 1976). Patients who met all the criteria were enrolled and given $200 \mathrm{mg}$ theophylline twice daily for 4 weeks (a run-in period). The patients had been receiving different doses of theophylline, or none, before the run-in period. In those patients who had been receiving higher doses, the dose was reduced to $200 \mathrm{mg}$ twice daily, as reported in previous studies, to prevent high serum concentrations (Kelly 1987; Barnes 1997). None of the patients was treated with anti-histamines, anti-leukotrienes, cromolyn, $\beta$-blockers, ACE inhibitors, oral prednisolone, and/or LABAs during the study. Some of the patients had 
discontinued these medications at least 4 weeks before enrollment. Patients were excluded if they had experienced an exacerbation within 4 weeks before enrollment. The use of a short-acting $\beta_{2}$-agonist or short-acting anticholinergic on demand was permitted.

Following a 4-week run-in period (the end of which was defined as the baseline), patients were randomized to two groups. In one group, $18 \mu \mathrm{g}$ of tiotropium was added on once daily from 6:00 to 8:00 am (combination group), and the other continued with the theophylline alone (theophylline alone group) for 8 weeks (the end of the treatment period). Patients who developed emesis or anorexia associated with the theophylline were withdrawn from the study. Smoking status and participation in rehabilitation programs were not altered during the trial.

Physical examinations, spirometry, and blood testing, including the monitoring of plasma concentrations of theophylline and MRC scoring, were performed at screening and baseline, and after 4 and 8 weeks of treatment. Spirometry was performed at least three times between 11:00 am and noon, and the best dataset was accepted. On the basis of the results of a previous study, these values were regarded as the nearpeak changes after tiotropium inhalation (Disse et al 1999). Adverse events were evaluated during the study (Figure 1).
Data on exacerbations of COPD were also collected throughout the trial. Information on exacerbation was obtained by direct questioning of each patient. Exacerbation was defined in accordance with the description by RodrignezRoisin (2000).

\section{Statistical analysis}

The number of subjects completing the study to the stage of primary end-point $\left(\mathrm{FEV}_{1}\right)$ testing was 61 , the experiment had $90 \%$ validity at the 5\% significance level in detecting differences between treatments, as reported in previous studies (Hirata et al 2003; Ichinose et al 2003).

Demographic data and MRC score were expressed as mean \pm SD. Comparisons in the demographic characteristics of patients with COPD between the combination and theophylline alone groups were analyzed by Fisher's exact test. All data on spirometry and the time course of percentage change in pulmonary function since the screening visit were expressed as means \pm SEM. Mean percentage changes between baseline (end of the run-in period) and after 4 and 8 weeks of treatment (treatment period) in each group were calculated and then compared. The unpaired $t$-test was used for comparison between the two groups. Two-way ANOVA was used for comparison of the time course data of each

\section{Combination therapy}

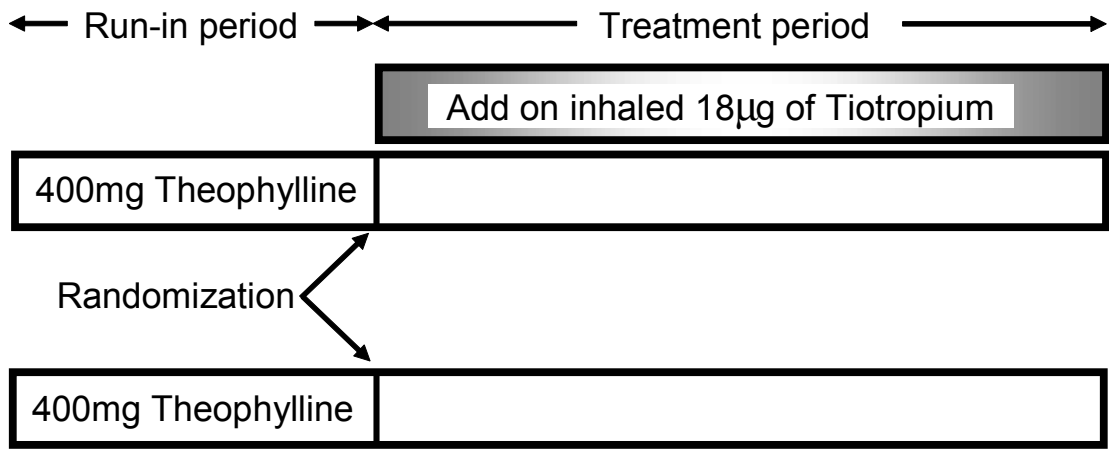

\section{Theophylline alone}

400mg Theophylline

Spirometry
MRC score ${ }^{\dagger}$
Chest radiogram $^{\text {Blood tests }}$

Screening (-4wks)

Pre- and Postbronchodilator

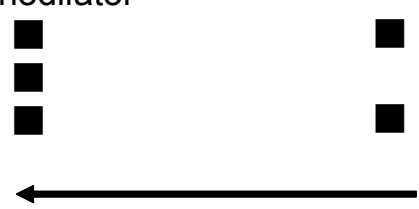

Baseline (0)

$4 \mathrm{wks}$

$8 w k s$

Adverse events

Figure I Study design.

Notes: ${ }^{\dagger}$ British Medical Research Council score. Combination therapy: theophylline with tiotropium. 
group at the baseline and after 4 and 8 weeks of treatment. MRC scoring of the time course data of each group was performed by non-parametric two-way ANOVA corrected by post-testing. The relationship between the changes in each spirometric parameter and MRC score was tested by Spearman's non-parametric correlation test. Data on the plasma concentration of theophylline were expressed as means $\pm \mathrm{SD}$ and compared between the two groups by an unpaired $t$-test. Differences were considered statistically significant when the $\mathrm{p}$ value was less than 0.05 .

\section{Results}

\section{Patients}

Demographic characteristics at the baseline are shown in Table 1. There was no significance difference in demographic characteristics between the two groups at the end of the run-in period. Seventy-seven COPD patients were matched to the entry criteria and enrolled in the study; they received theophylline (200 mg twice daily) for 4-weeks as a run-in period. During the run-in period, 13 patients were withdrawn from the study: 7 patients had adverse events associated with the theophylline (anorexia, 4; emesis, 1; ischuria, 1; and stomatitis, 1); 4 patients refused for personal reasons to continue; 1 patient had accompanying asthma, and one had an exacerbation of COPD. During the 8-week treatment period, two and one patient dropped out from the combination and theophylline alone groups, respectively. Finally, data on 61 COPD patients (31 combination; 30 theophylline alone) were used in the analysis (Figure 2). No subject in either group experienced disease exacerbation from baseline to 8 weeks.

\section{Pulmonary function tests}

The FVC and $\mathrm{FEV}_{1}$ values in the combination therapy group were significantly increased 4 and 8 weeks after the addition of tiotropium, when compared with the baseline (Figure $3 \mathrm{a}, \mathrm{b}$ ). The increase in $\mathrm{FEV}_{1}$ from the baseline was $0.17 \pm 0.03 \mathrm{~L}$ at 4 weeks and $0.21 \pm 0.03 \mathrm{~L}$ at 8 weeks. In contrast, these effects were not observed in the theophylline-alone group. The percentage changes in FVC and $\mathrm{FEV}_{1}$ from the baseline were significantly increased at 4 and at 8 weeks in the combination therapy group, but not in the theophylline-alone group (Figure $3 \mathrm{c}, \mathrm{d}$ ). In addition, the percentage change in $\mathrm{FEV}_{1}$ in the combination therapy group was significantly greater than that in the theophylline-alone group.

Figure 4 shows the results from 42 subjects from both groups who did not receive theophylline at screening (25 combination; 17 theophylline-alone). Theophylline-alone group did not cause a significant improvement in pulmonary function and symptoms over the 12 weeks (4-week run-in plus 8-week therapeutic period). However, in the combination therapy group, FVC and $\mathrm{FEV}_{1}$ were significantly increased after the addition of tiotropium.

Table I Characteristics of patients with COPD at baseline

\begin{tabular}{|c|c|c|c|}
\hline & $\begin{array}{l}\text { Theophylline-alone group } \\
(n=30)\end{array}$ & $\begin{array}{l}\text { Combination group } \\
(n=3 I)\end{array}$ & p value \\
\hline Age, $y r \pm S D$ & $71.8 \pm 8.1$ & $68.4 \pm 9.1$ & NS \\
\hline Sex, Female/Male & $2 / 28$ & $1 / 30$ & NS \\
\hline Smoking history, Pack-yr \pm SD & $66.7 \pm 57.2$ & $57.5 \pm 31.5$ & NS \\
\hline Current smoker, \% patients & $13(44.3)$ & 14 (45.2) & NS \\
\hline Body mass index, $\mathrm{kg} / \mathrm{m}^{2}$ & $21.8 \pm 3.6$ & $22.6 \pm 3.0$ & NS \\
\hline \multicolumn{4}{|l|}{ Severity of disease, $n(\%)$} \\
\hline Mild (stage I) & $8(26.7)$ & $4(12.9)$ & NS \\
\hline Moderate (stage II) & $12(40.0)$ & $13(41.9)$ & NS \\
\hline Severe (stage III) & $10(33.3)$ & 14 (45.2) & NS \\
\hline MRC dyspnoea score, mean \pm SD & $2.0 \pm 1.1$ & $2.0 \pm 1.1$ & NS \\
\hline $\mathrm{FVC}(\mathrm{L})$, mean $\pm \mathrm{SD}$ & $2.8 \pm 0.9$ & $3.0 \pm 0.8$ & NS \\
\hline $\mathrm{FEV}_{\mathrm{l}} / \mathrm{FVC}(\%)$, mean $\pm \mathrm{SD}$ & $49.8 \pm 12.4$ & $47.1 \pm 12.6$ & NS \\
\hline \multicolumn{4}{|l|}{ Pre-medications, n (\%) } \\
\hline Theophylline & II (36.7) & $6(19.4)$ & NS \\
\hline Long-acting $\beta_{2}$-agonist & $4(13.3)$ & $\mathrm{I}(3.2)$ & NS \\
\hline Short-acting $\beta_{2}$-agonist & $7(23.3)$ & $2(6.5)$ & NS \\
\hline Short-acting anticholinergic drug & $2(6.7)$ & $2(6.5)$ & NS \\
\hline Inhaled corticosteroid & $5(16.7)$ & $2(6.5)$ & NS \\
\hline
\end{tabular}

Abbreviations: $\mathrm{FEV}_{1}$, forced expiratory volume in one second; FVC, forced vital capacity; NS, not significant; SD, standard deviation. 


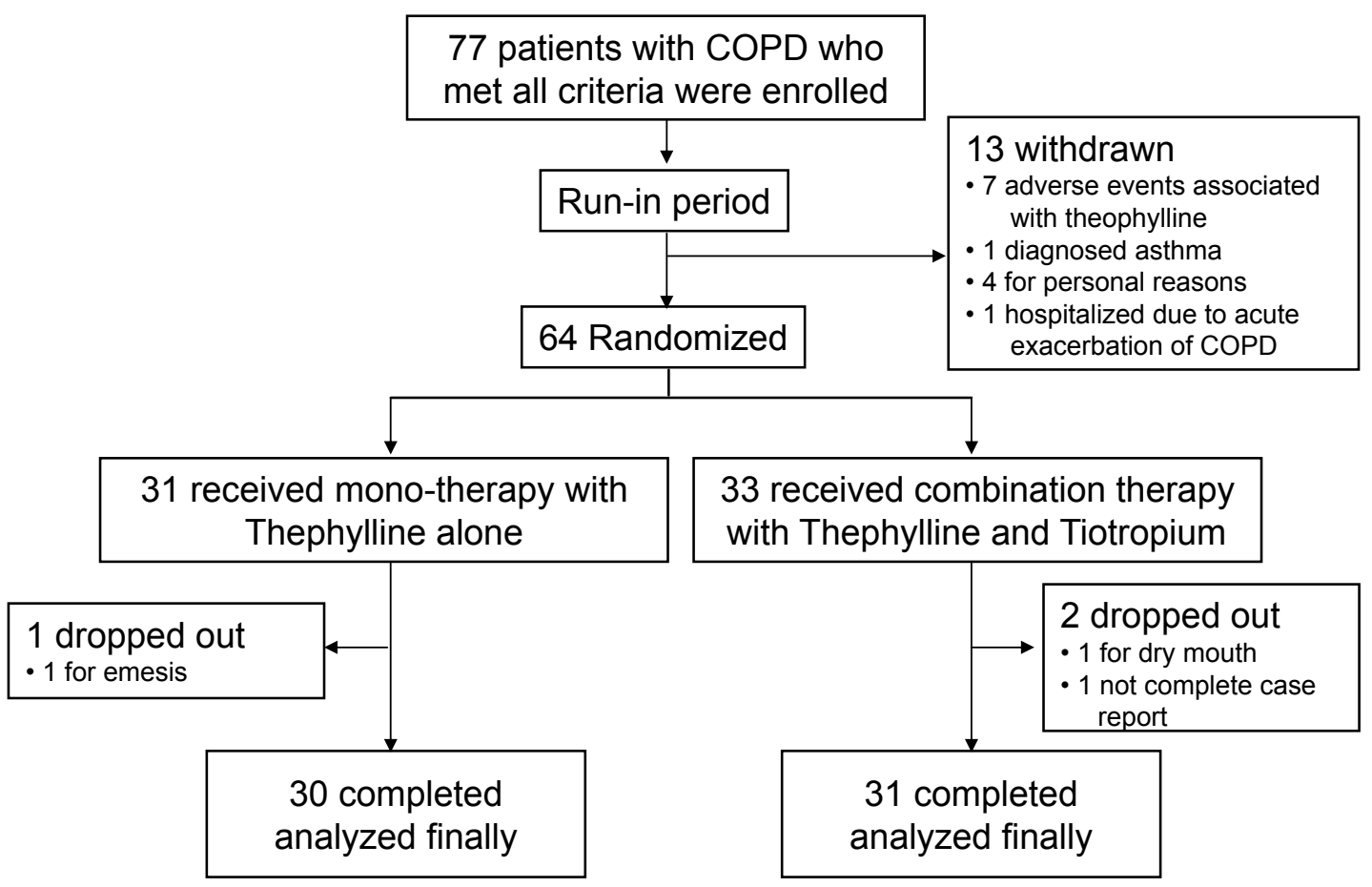

Figure 2 Trial profile.
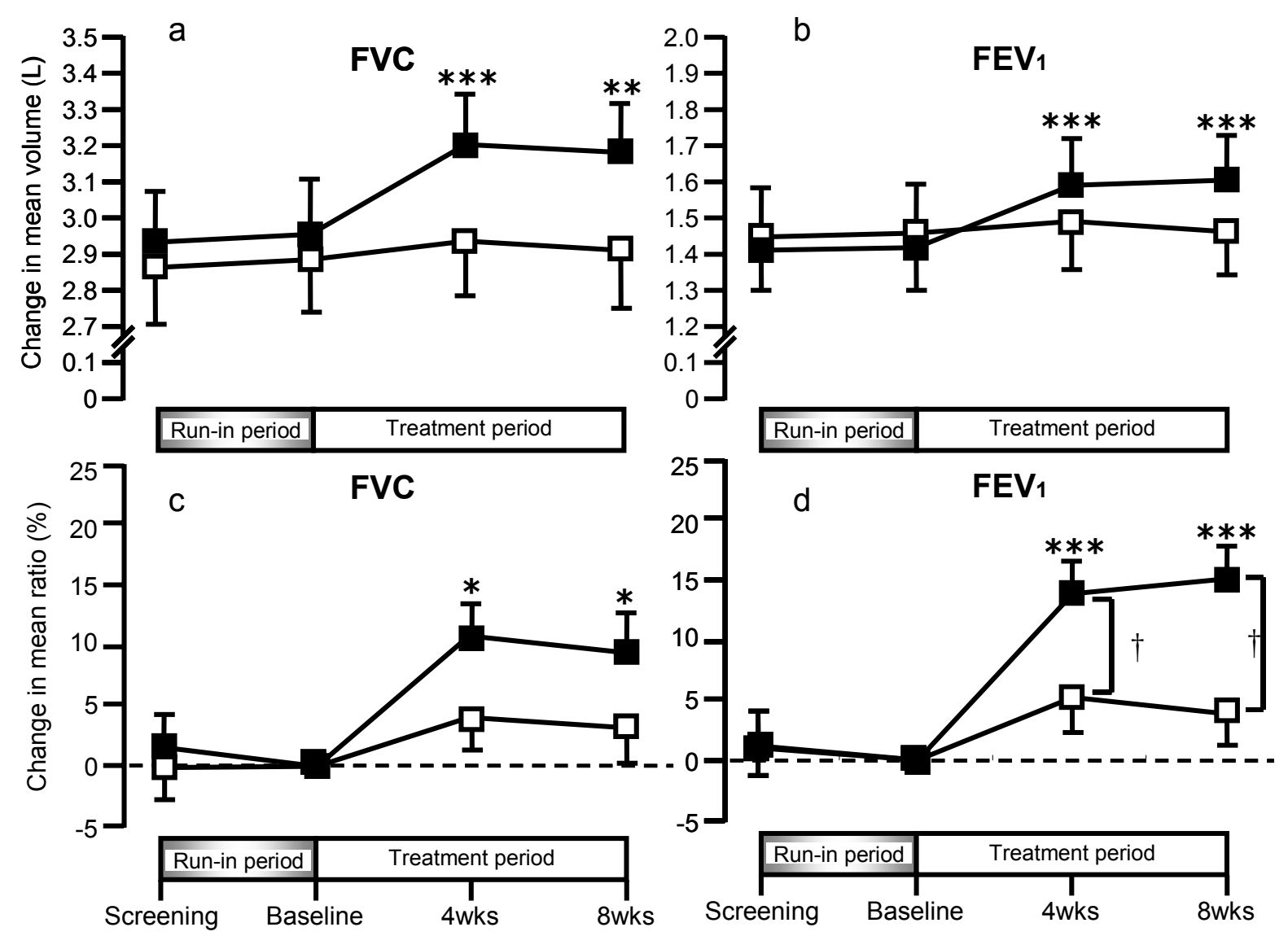

Figure 3 Changes in FVC and FEV, in the theophylline alone (white squares) and the combination therapy group (black squares). In a and b, absolute values of FVC and $\mathrm{FEV}$, are shown. In $\mathrm{c}$ and $\mathrm{d}$, percentage changes in FVC and $\mathrm{FEV}$, from the baseline are shown.

Notes: ${ }^{*} p<0.05,{ }^{* *} p<0.01$, ${ }^{* * *} p<0.001$ compared with baseline values. ${ }^{\dagger} p<0.05$ between two groups.

Abbreviations: $\mathrm{FVC}$, forced vital capacity; $\mathrm{FEV}_{1}$, forced expiratory volume in one second. 

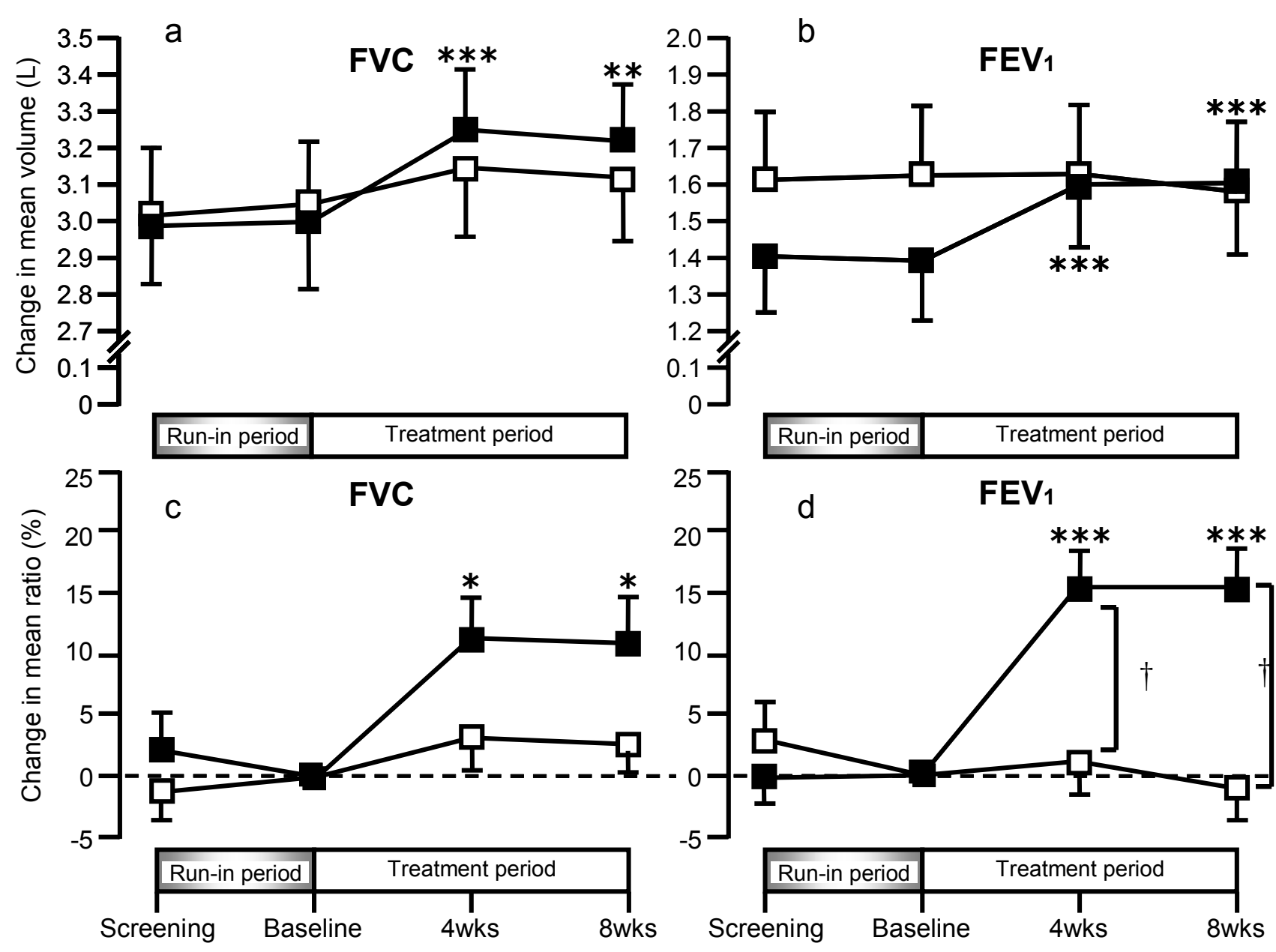

Figure 4 Changes in FVC and FEV, in the theophylline-alone (white squares, $n=17$ ) and the combination therapy group (black squares, $\mathrm{n}=25$ ), in patients who did not receive regular treatment with theophylline at the time of screening. In a and b, absolute values of FVC and FEV, are shown. In c and d, percentage changes in FVC and FEV from the baseline are shown.

Notes: ${ }^{*} \mathrm{p}<0.05,{ }^{* *} \mathrm{p}<0.01,{ }^{* * *} \mathrm{p}<0.001$ compared with the baseline values. ${ }^{\dagger} \mathrm{p}<0.05$ between two groups.

Abbreviations: FVC, forced vital capacity; $\mathrm{FEV}_{1}$, forced expiratory volume in one second.

After 8 weeks of treatment, VC, inspiratory capacity (IC), peak expiratory flow rate (PEFR), $\dot{\mathrm{V}}_{50}$, and $\dot{\mathrm{V}}_{25}$ were significantly higher than the baseline values in the combination group. These effects were not observed in the theophyllinealone group (Figure 5).

\section{MRC score}

MRC score was analyzed in 59 of 61 patients (two patients withdrew from the study at the stage of MRC scoring). MRC scores in the theophylline-alone group $(\mathrm{n}=29)$ at screening, baseline, and 4 and 8 weeks after treatment were $2.00 \pm 1.10$, $1.75 \pm 1.14,2.04 \pm 0.94$, and $2.04 \pm 1.21$, respectively. The respective MRC scores in the combination group $(\mathrm{n}=30)$ were $2.03 \pm 1.10,2.03 \pm 1.19,1.57 \pm 1.14$, and $1.57 \pm 1.14$. When compared with the baseline values, the mean MRC score in the combination group was significantly decreased by $0.46(\mathrm{p}<0.01)$ and $0.46(\mathrm{p}<0.05)$ at 4 and 8 weeks after treatment, respectively. The improvement was small but clinically meaningful, because the changes in MRC score were greater than those in a previous study (Akamatsu et al 2007). In contrast, there was no significant change in the theophylline-alone group when compared with baseline. There was no significant difference in MRC score between the two groups at each time point (Figure 6a).

Next, we performed a sub-analysis of 42 of these 59 patients who were not receiving theophylline at screening to determine the therapeutic effects of theophylline itself. MRC scores at screening, baseline, and 4 and 8 weeks after treatment in the theophylline-alone group $(\mathrm{n}=17)$ were $1.85 \pm$ $1.14,1.74 \pm 1.15,1.95 \pm 1.03$, and $1.88 \pm 1.32$, respectively. The respective MRC scores in the combination group $(\mathrm{n}=25)$ were $2.08 \pm 1.15,2.12 \pm 1.24,1.60 \pm 1.15$, and $1.58 \pm 1.21$. When compared with the baseline values, the mean MRC score in the combination group was significantly decreased 

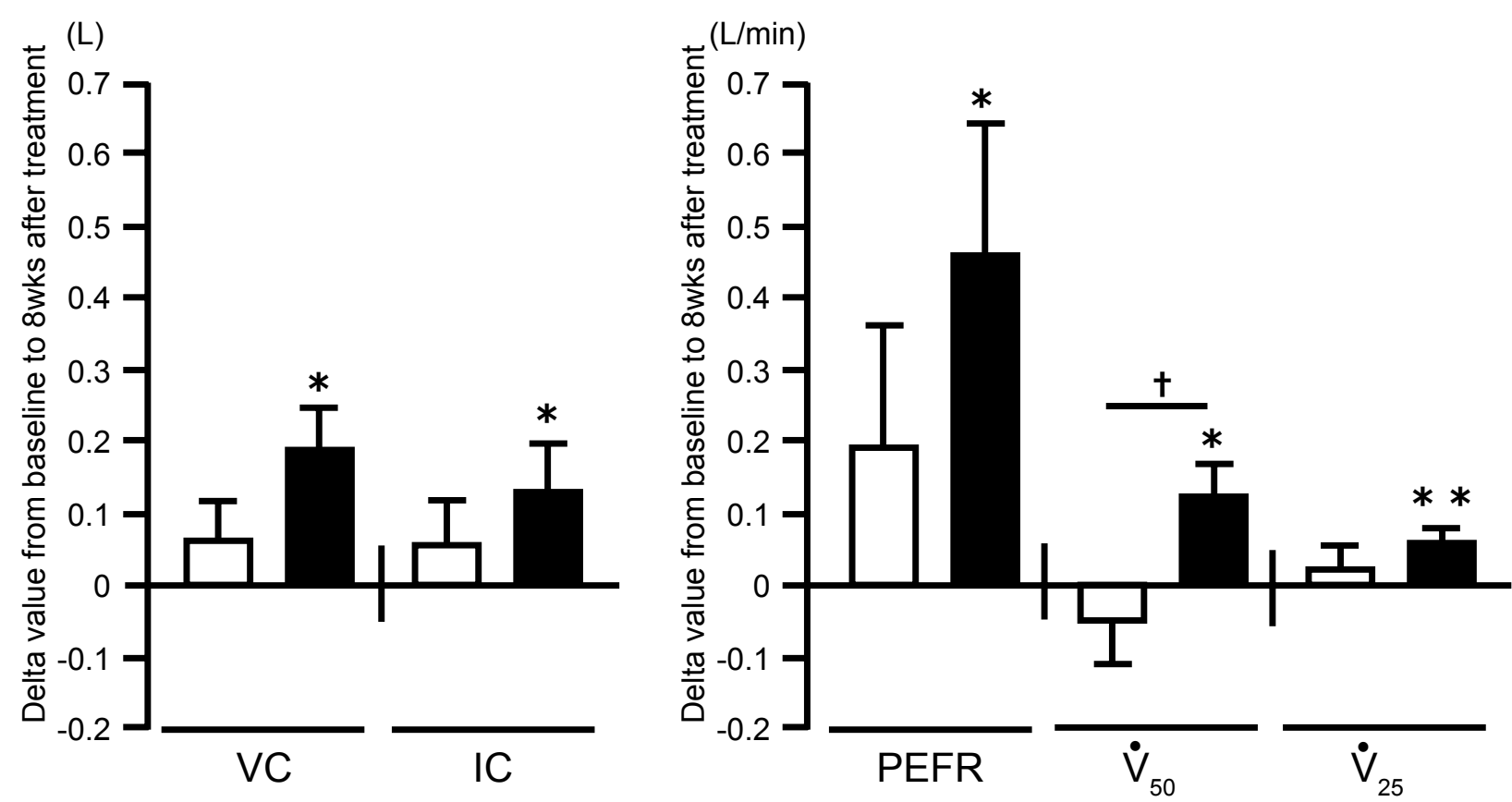

Figure 5 Changes in VC, IC, PEFR, $\dot{\mathrm{V}}_{50}$ and $\dot{\mathrm{V}}_{25}$ at 8 weeks. Changes in VC, IC, PEFR, $\dot{\mathrm{V}}_{50}$, and $\dot{\mathrm{V}}_{25}$ at 8 weeks were analyzed in theophylline-alone (white bars, $\left.\mathrm{n}=26\right)$ and combination therapy (solid bars, $\mathrm{n}=30$ ) groups.

Notes: ${ }^{*} \mathrm{p}<0.05$ compared with screening values. ${ }^{\dagger} \mathrm{p}<0.05$ between two groups.

Abbreviations: IC, inspiratory capacity; PEFR, peak expiratory flow rate; VC, vital capacity.

by $0.52(\mathrm{p}<0.01)$ and $0.54(\mathrm{p}<0.05)$ at 4 and 8 weeks, respectively, after treatment (Figure 6b).

\section{Physical examination}

No significant difference was observed between the two groups in terms of respiratory rates, blood pressure, heart rates, body temperature, and oxygen saturation of arterial blood by pulse oximeter at the screening visit, at the baseline, and after 4 and 8 weeks of treatment with tiotropium (data not shown).

Serum theophylline concentrations at the baseline and after 4 and 8 weeks of treatment were $8.6 \pm 5.0,8.9 \pm 5.5$, and $8.5 \pm 4.7 \mu \mathrm{g} / \mathrm{mL}$ in the theophylline-alone group, and $9.5 \pm 5.7,9.4 \pm 3.6$, and $9.1 \pm 4.9 \mu \mathrm{g} / \mathrm{mL}$ in the combination therapy group, respectively. There were no significant differences between the two groups at any time. Serum theophylline levels greater than $20 \mu \mathrm{g} / \mathrm{mL}$ were not observed in any patient.

\section{Adverse events}

During the run-in period, 7 patients dropped out because of theophylline-related adverse events, as described above. We observed 9 adverse events during the treatment period. Two and 7 adverse events were observed in the theophylline-alone group and the combination therapy group, respectively. In the theophylline-alone group, these events were anorexia $(n=1)$ and hematuria $(\mathrm{n}=1)$. In the combination therapy group, they were dry mouth $(n=2)$, pharyngolaryngeal paresthesia $(n=3)$, fatigue $(n=1)$, and bitter taste $(n=1)$. One of the patients with emesis dropped out of the theophylline-alone group, and one with dry mouth and one with pharyngolaryngeal paresthesia dropped out of the combination therapy group.

\section{Discussion}

To our knowledge, this is the first study to show the efficacy and safety of tiotropium add-on therapy in COPD patients treated with theophylline. We demonstrated that add-on therapy with tiotropium significantly improved the MRC dyspnea score and pulmonary function in COPD patients already being treated with theophylline. According to the GOLD guidelines, combination therapy with different kinds of bronchodilators is recommended for COPD patients, because it can improve efficacy without increasing the risk of side effects, as compared with increasing the dose of monotherapy (Gold 2006).

Previous studies have reported that treatment with relatively low dose of theophylline has anti-inflammatory effects in COPD patients (Culpitt et al 2002; Kobayashi et al 2004; Hirano et al 2006). These patients were treated with theophylline at $400 \mathrm{mg} / \mathrm{day}$, and/or plasma levels 
(a) MRC grade

(b)

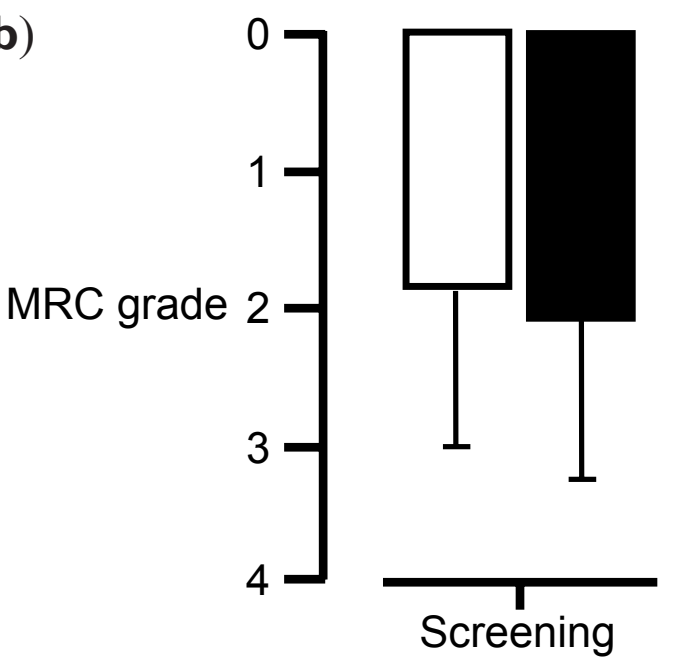

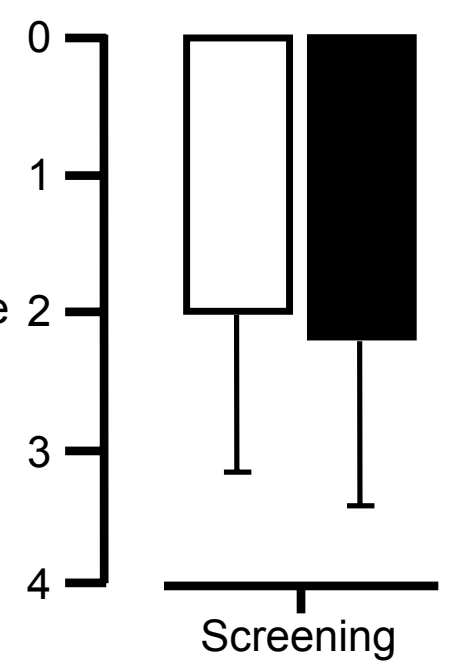
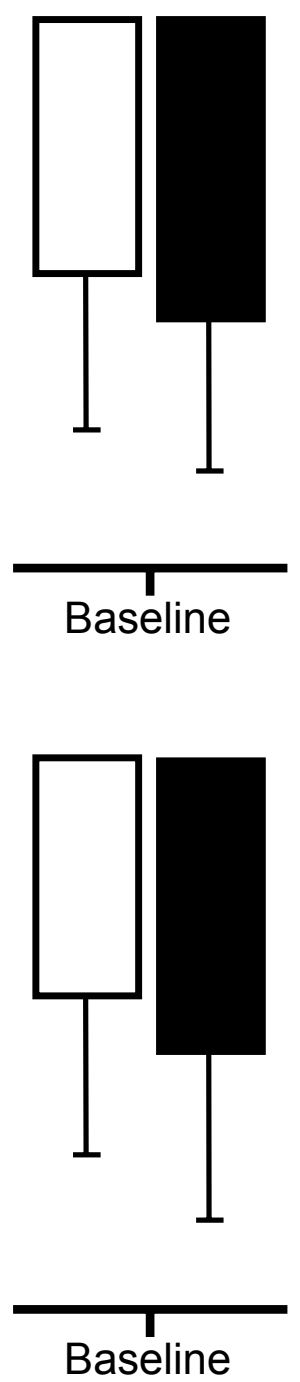
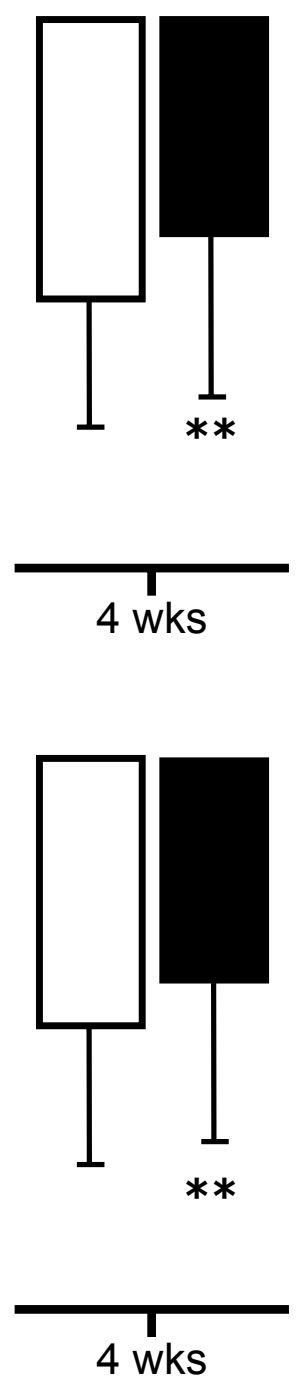
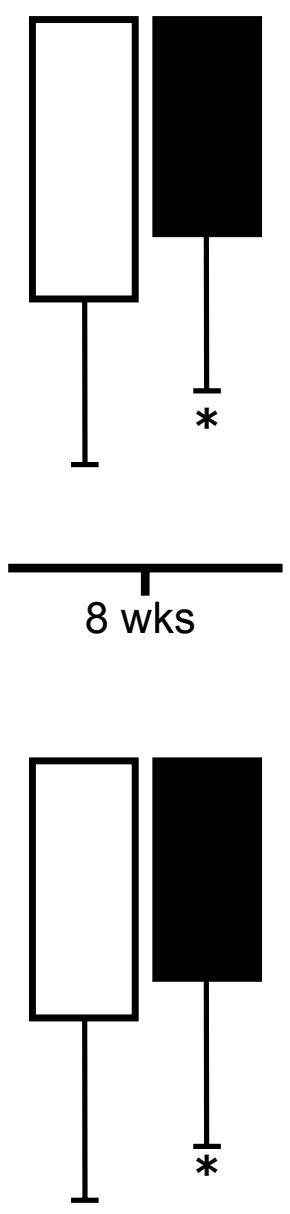

8 wks

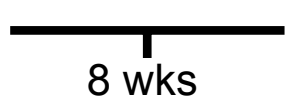

Figure 6 British Medical Research Council (MRC) scores 4 and 8 weeks after the addition of tiotropium. (a) MRC scores 4 and 8 weeks after the addition of tiotropium were analyzed in theophylline-alone (white bars, $n=29$ ) and combination therapy (solid bars, $n=30$ ) groups. (b) MRC scores 4 and 8 weeks after the addition of tiotropium were analyzed in 42 patients who were not receiving theophylline at the time of screening: theophylline-alone (white bars, $n=17$ ) and combination therapy (solid bars, $n=25$ ). Notes: $*_{p}<0.05, p<0.01$ compared with baseline values.

of theophylline were approximately 5 to $10 \mathrm{mg} / \mathrm{L}$. These concentrations of theophylline had anti-inflammatory effects. However, these studies did not determine whether theophylline had clinical benefits on pulmonary function or physical condition in COPD patients. The Japanese Respiratory Society's guidelines for the diagnosis and treatment of COPD suggested that low dose of theophylline may be effective for COPD patients, as high doses of theophylline have toxic effects (Guidelines for the Diagnosis and Treatment of COPD 2006). On the basis of these studies, we treated COPD patients with $400 \mathrm{mg}$ theophylline (200 mg twice daily). Plasma levels of theophylline were approximately 8 to $10 \mathrm{mg} / \mathrm{L}$ in these patients, and theophylline alone did not improve pulmonary function $\left(\mathrm{FEV}_{1}\right)$ or MRC scores in 30 COPD patients analyzed. Moreover, in 17 patients who were not receiving theophylline at screening, treatment with theophylline alone did not improve MRC score or FEV $\mathrm{F}_{1}$. The possibility remains that this concentration of theophylline in the plasma may not exert sufficient bronchodilatation (Mitenko and Ogilvie 1973). Here we evaluated whether the combination of theophylline and tiotropium could improve $\mathrm{FEV}_{1}$ and MRC scores in COPD patients, and we compared our results with those of previous studies in Japan (Hirata et al 2003; Ichinose et al 2003).

A study that compared the effects of the short-acting anticholinergic ipratropium and theophylline reported that 
improvement of pulmonary function and exercise endurance was significantly greater in the combination therapy group than in each monotherapy group (Tsukino et al 1998). In addition, a combination of the short-acting anti-cholinergic oxitropium and theophylline improved QOL to a significantly greater extent than did each monotherapy (Bellia et al 2002). Furthermore, combination treatment with a short-acting $\beta_{2}$-agonist, a short-acting anticholinergic agent, and oral theophylline led to significantly greater improvement in $\mathrm{FEV}_{1}$ compared with the results of monotherapy, without any severe adverse effects (Karpel et al 1994).

Long-acting bronchodilators have recently become standard medicines in the pharmacological treatment of COPD (Gold 2006). Therefore, the establishment of combination therapy for COPD with long-acting bronchodilators is an expected trend. Combination of the LABA salmeterol with theophylline leads to significantly better pulmonary functions, greater improvement in symptoms, improved reduction in the use of short-acting $\beta_{2}$-agonists, and decrease in exacerbation frequency compared with the use of theophylline alone (Zuwallack et al 2001). In both stable COPD patients and those with exacerbations, combination therapy with the inhaled LABA formoterol and the inhaled long-acting anticholinergic tiotropium improves pulmonary function indicators such as $\mathrm{FEV}_{1}, \mathrm{IC}$, and FVC to a significantly greater extent than is seen with each agent alone (Di Marco et al 2006; Van Noord et al 2006). A previous study also showed additional clinical improvement when COPD patients were treated with theophylline added to salmeterol (Zuwallack et al 2001). However, evidence of the effects of combination therapy with long-acting bronchodilators, especially anticholinergics and theophylline, is still scant.

One recent study reported the effect of combination therapy with tiotropium and theophylline (Cazzola and Gabriella Matera 2007). They investigated the additive effect of theophylline in patients with stable COPD who were receiving both tiotropium and formoterol. Although their findings question the importance of adding theophylline in stable COPD patients already being treated with two longacting bronchodilators, they also indicate that some patients may benefit from theophylline because of symptomatic improvement. We chose to investigate the effects of adding tiotropium in patients already treated with theophylline because theophylline is widely used for COPD treatment, both in Japan and worldwide (Ichinose et al 2006).

Dyspnea upon exercise is one of the most important symptoms in patients with COPD. We used the MRC dyspnea score to assess symptoms: the MRC questionnaire can easily classify symptom severity. We demonstrated that the mean MRC dyspnea score in patients with combination therapy improved significantly after both 4 and 8 weeks of tiotropium add-on therapy.

The beneficial effect of combination therapy might be attributable to the different mechanisms of bronchodilation (Thirstrup 2000). Theophylline had been reported to have extrapulmonary effects, such as increased diaphragmatic contractility and reversed diaphragm fatigue, although the validity of these effects remains controversial (Aubier et al 1981). There is also increasing evidence that low-dose theophylline has anti-inflammatory effects in asthma and COPD (Culpitt et al 2002; Cosio et al 2004; Barnes et al 2005).

The effects of treatment with tiotropium alone on pulmonary function, when compared with placebo, include improvements in peak expiratory flow volume, $\mathrm{FEV}_{1}$, FVC, VC, and IC (Casaburi et al 2002; Vincken et al 2002; Brusasco et al 2003; Celli et al 2003; O’Donnell et al 2004; Van Noord et al 2006). Our findings confirmed these previous observations. In the study of Japanese COPD patients, the increase in peak $\mathrm{FEV}_{1}$ with tiotropium alone was $0.20 \pm 0.02 \mathrm{~L}$ after 6 months of treatment (Hirata et al 2003; Ichinose et al 2003). In our patients, addition of tiotropium to theophylline increased the mean $\mathrm{FEV}_{1}$ by $0.17 \pm 0.03 \mathrm{~L}$ and $0.21 \pm 0.03 \mathrm{~L}$ after 4 and 8 weeks, respectively. These increases in $\mathrm{FEV}_{1}$ were similar to those in other investigations (Hirata et al 2003; Ichinose et al 2003). Our present study did not include a group of patients treated with tiotropium alone, so we were unable to assess whether there was any benefit of adding theophylline to patients treated with tiotropium. The above-mentioned recent study in which the add-on effect of theophylline was investigated in patients already being treated with tiotropium and formoterol reported a limited effect of theophylline add-on (Cazzola and Gabriella Matera 2007). Evaluation of all of these results together indicates that tiotropium is a useful addition in COPD patients already treated with theophylline.

\section{Acknowledgments}

We especially thank Dr Gail M Gauvreau of the Asthma Research Group, McMaster University, Canada, for critical reading of this manuscript. This work was supported by Nippon Boehringer Ingelheim Co, Ltd (Tokyo, Japan) and by a Grant-in-Aid for Scientific Research (B) (no. 18390244) and Grants-in-Aid for Scientific Research (B) (no. 17390244) and Exploratory Research (no. 18659244) from the Ministry of Education, Science, Sports, and Culture of Japan. 


\section{References}

Akamatsu K, Yamagata T, Takahashi T, et al. 2007. Improvement of pulmonary function and dyspnea by tiotropium in COPD patients using a transdermal beta(2)-agonist. Pulm Pharmacol Ther, 20:701-7.

Anzueto A, Tashkin D, Menjoge S, et al. 2005. One-year analysis of longitudinal changes in spirometry in patients with COPD receiving tiotropium. Pulm Pharmacol Ther, 18:75-81.

Aubier M, De Troyer A, Sampson M, et al. 1981. Aminophylline improves diaphragmatic contractility. $N$ Engl J Med, 305:249-52.

Barnes PJ. 1997. Current therapies for asthma. Promise and limitations. Chest, 111:17S-26S.

Barnes PJ, Adcock IM and Ito K. 2005. Histone acetylation and deacetylation: importance in inflammatory lung diseases. Eur Respir $J$, 25:552-63.

Bellia V, Foresi A, Bianco S, et al. 2002. Efficacy and safety of oxitropium bromide, theophylline and their combination in COPD patients: a double-blind, randomized, multicentre study (BREATH Trial). Respir Med, 96:881-9.

Brusasco V, Hodder R, Miravitlles M, et al. 2003. Health outcomes following treatment for six months with once daily tiotropium compared with twice daily salmeterol in patients with COPD. Thorax, 58:399-404.

Casaburi R, Mahler DA, Jones PW, et al. 2002. A long-term evaluation of once-daily inhaled tiotropium in chronic obstructive pulmonary disease. Eur Respir J, 19:217-24.

Cazzola M, Gabriella Matera M. 2007. The additive effect of theophylline on a combination of formoterol and tiotropium in stable COPD: a pilot study. Respir Med, 101:957-62.

Celli, B, ZuWallack R, Wang S, et al. 2003. Improvement in resting inspiratory capacity and hyperinflation with tiotropium in COPD patients with increased static lung volumes. Chest, 124:1743-8.

Cosio BG, Tsaprouni L, Ito K, et al. 2004. Theophylline restores histone deacetylase activity and steroid responses in COPD macrophages. J Exp Med, 200:689-95.

Culpitt SV, de Matos C, Russell RE, et al. 2002. Effect of theophylline on induced sputum inflammatory indices and neutrophil chemotaxis in chronic obstructive pulmonary disease. Am J Respir Crit Care Med, 165:1371-6.

Di Marco F, Verga M, Santus P, et al. 2006. Effect of formoterol, tiotropium, and their combination in patients with acute exacerbation of chronic obstructive pulmonary disease: a pilot study. Respir Med, 100:1925-32.

Disse B, Speck GA, Rominger KL, et al. 1999. Tiotropium (Spiriva): mechanistical considerations and clinical profile in obstructive lung disease. Life Sci, 64:457-64.

Donohue JF. 2005. Combination therapy for chronic obstructive pulmonary disease: clinical aspects. Proc Am Thorac Soc, 2:272-81; discussion: $90-1$.

Dusser D, Bravo ML, Iacono P. 2006. The effect of tiotropium on exacerbations and airflow in patients with COPD. Eur Respir J, 27:547-55.

[GOLD] Global Initiative for Chronic Obstructive Lung Disease. 2006. Global strategy for the diagnosis, management and prevention of chronic obstructive pulmonary disease. NHLBI/WHO workshop report. Bethesda, National Heart, Lung and Blood Institute [online]. Accessed 11 November 2006. URL: http://www.goldcopd.com.

Guidelines for the diagnosis and treatment of COPD, 2006. Guidelines for the diagnosis and treatment of COPD, 2nd edition. Committee for the second edition of the COPD guidelines of the Japanese Respiratory Society [online]. URL: http://www.jrs.or.jp/quicklink/glsm/guideline/ nopass_pdf/copd_summary_e.pdf.

Guyatt Gh, Townsend M, Pugsley So, et al. 1987. Bronchodilators in chronic air-flow limitation. Effects on airway function, exercise capacity, and quality of life. Am Rev Respir Dis, 135:1069-74.
Hirano T, Yamagata T, Gohda M, et al. 2006. Inhibition of reactive nitrogen species production in COPD airways: comparison of inhaled corticosteroid and oral theophylline. Thorax, 61:761-6.

Hirata K, Nishimura M, Ichinose M, et al. 2003. Tiotropium once daily improves health status in Japanese patients with COPD. Am J Respir Crit Care Med, 167:A94.

Ichinose M, Nishimura M, Hirata K, et al. 2003. Tiotropium once daily improves spirometry over 24 hours in Japanese patients with COPD. Am J Respir Crit Care Med, 167:A95.

Ichinose M, Fukuchi, Y, Nagai, A, et al. 2006. Large-scale telephone survey on burden of patients with chronic obstructive pulmonary disease (COPD) in Japan: confronting COPD. Respirology, 11:A154.

Ito K, Lim S, Caramori G, et al. 2002. A molecular mechanism of action of theophylline: Induction of histone deacetylase activity to decrease inflammatory gene expression. Proc Natl Acad Sci USA, 99:8921-6.

Jackson RH, McHenry JI, Moreland FB, et al. 1964. Clinical evaluation of elixophyllin with correlation of pulmonary function studies and theophylline serum levels in acute and chronic asthmatic patients. Dis Chest, 45:75-85.

Karpel JP, Kotch A, Zinny M, et al. 1994. A comparison of inhaled ipratropium, oral theophylline plus inhaled beta-agonist, and the combination of all three in patients with COPD. Chest, 105:1089-94.

Kelly HW. 1987. Theophylline toxicity. In: Jenne JW, Murphy S, Dekker M eds. Drug therapy for asthma. New York, pp 925-51.

Kobayashi, M, Nasuhara Y, Betsuyaku T, et al. 2004. Effect of low-dose theophylline on airway inflammation in COPD. Respirology, 9:249-54.

Mitenko PA, Ogilvie RI. 1973. Rational intravenous doses of theophylline. N Engl J Med, 289:600-3.

Moor-Jankowski J. 1976. Primate animals for biomedical research evaluation by the British Medical Research Council Laboratory Animal Centre. A critical review. J Med Primatol, 5:365-71.

Murciano D, Auclair MH, Pariente R, et al. 1989. A randomized, controlled trial of theophylline in patients with severe chronic obstructive pulmonary disease. $N$ Engl J Med, 320:1521-5.

Niewoehner DE, Rice K, Cote C, et al. 2005. Prevention of exacerbations of chronic obstructive pulmonary disease with tiotropium, a once-daily inhaled anticholinergic bronchodilator: a randomized trial. Ann Intern Med, 143:317-26.

O'Donnell DE, Fluge T, Gerken F, et al. 2004. Effects of tiotropium on lung hyperinflation, dyspnoea and exercise tolerance in COPD. Eur Respir J, 23:832-40.

Rodriguez-Roisin R. 2000. Toward a consensus definition for COPD exacerbations. Chest, 117:398S-401S

Sullivan P, Bekir S, Jaffar Z, et al. 1994. Anti-inflammatory effects of lowdose oral theophylline in atopic asthma. Lancet, 343:1006-8.

Thirstrup S. 2000. Control of airway smooth muscle tone: II-pharmacology of relaxation. Respir Med, 94:519-28.

Tsukino M, Nishimura K, Ikeda A, et al. 1998. Effects of theophylline and ipratropium bromide on exercise performance in patients with stable chronic obstructive pulmonary disease. Thorax, 53:269-73.

Turner-Warwick M. 1957. Study of theophylline plasma levels after oral administration of new theophylline compounds. Br Med J, 2:67-9.

van Noord JA, Aumann JL, Janssens E, et al. 2006. Effects of tiotropium with and without formoterol on airflow obstruction and resting hyperinflation in patients with COPD. Chest, 129:509-17.

Vincken W, van Noord JA, Greefhorst AP, et al. 2002. Improved health outcomes in patients with COPD during 1 yr's treatment with tiotropium. Eur Respir J, 19:209-16.

ZuWallack RL, Mahler DA, Reilly D, et al. 2001. Salmeterol plus theophylline combination therapy in the treatment of COPD. Chest, 119:1661-70. 


\section{*Appendix}

The Kurume COPD Study Group includes Dr Toshinobu Yokoyama and Dr Tomoko Kamimura, (Kurume University); Dr Kazuhito Taguchi, (National Hospital Organization Kyushu Medical Center); Dr Rumi Gohara and Dr Yoshikazu Tominaga (Yame General Hospital); Dr Toru Rikimaru and Dr Mamoru Nishiyama (Saiseikai Futsukaichi Hospital); Dr Koichi Azuma (Social Insurance Tagawa Hospital); Dr Kazuko Matsunaga (National Hospital Organization Omuta Hospital); and Dr Hideyuki Koga (Keisinkai Hospital). 
